\title{
Perspectives for executive information, decision support and information management in the extended enter- prise
}

Mertins K., Krause O.

Fraunhofer Institute for

Production Systems and Design Technology

Pascalstr 8-9

10587 Berlin

Tel: $\quad+49 /(0) 3039006-233,-345$

Fax: $+49 /(0) 3932503$

e-mail:kai.mertins@ipk.fhg.de,oliver.krause@ipk.fhg.de

\begin{abstract}
In the context of goal-planning, performance measurement and decision support, information is a key resource for the extended enterprise. With the increasing complexity of the value chain, new concepts for organisational control are required. The Management Information Logistics Process is particularly crucial in this context.

This paper will develop requirements and identify research directions to meet the challenge for management information logistics and decision support for the extended enterprise.
\end{abstract}

\section{Keywords}

Management Information Logistics, Knowledge Management, Decision Support, Goal Planning, Strategy Development, Benchmarking, Management Information Systems, Executive Information Systems, OLAP, Data Warehouse, 


\section{DECISIONS AND INFORMATION}

The decisive factors of competitive success today are time and information. It is not any more the big who outperforms the small, but the fast who outperforms the slow. Competitive success of a company does not only largely depend on its ability to adapt products and processes to a rapidly changing environment. For the longterm generation of value it is required to anticipate change and to proactively create markets and the products and services to feed them.

To do so, entrepreneurial decisions have to be taken. These decisions determine the extend and the direction of change required. Decisions are a central domain of research in management science (Adam 1996). The reason is that decisions do control activities. Reasonable entrepreneurial decisions are based on the availability of relevant and correct information. Therefore information logistics is a critical process and information itself is a critical resource.

Krcmar already pointed out that there is theory-gap concerning a proper definition of the term information (Krcmar 1991). We suggest to consider information as relevant goal-oriented knowledge. This criterion is depending first of all on the decision-domain defined by goals and tasks and secondly on the information-user.

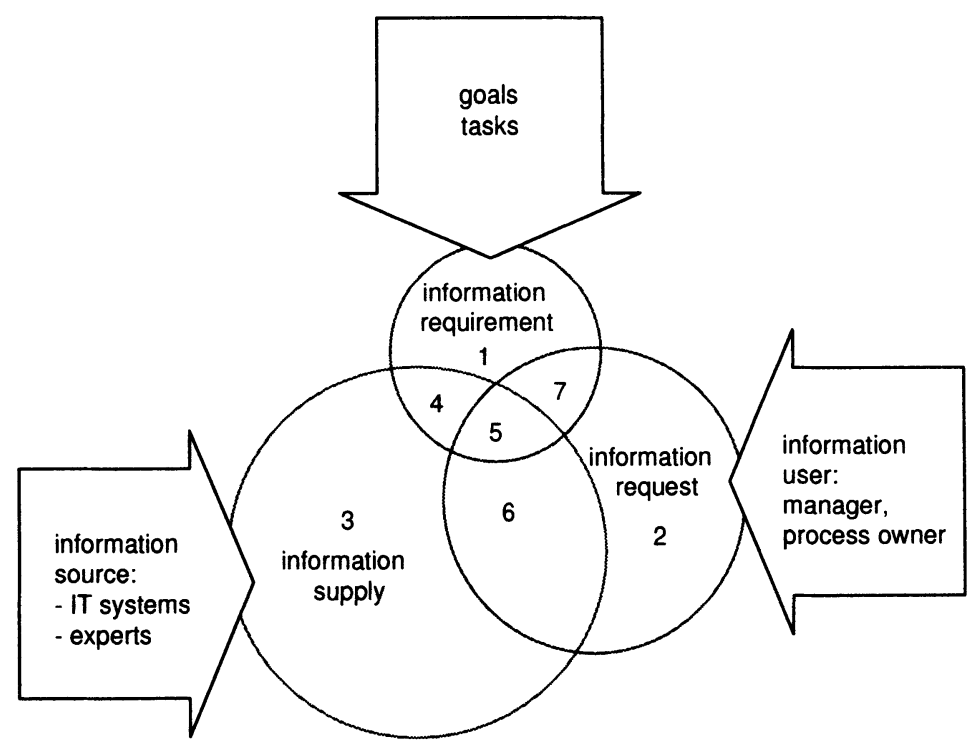

Figure 1 Requirement, request and supply of information

The widespread incoherence of information requirement, supply and request is illustrated in figure 1. Relevant, goal-oriented knowledge (1) is required to take reasonable decisions. However, process-owners tend to request more information 
(2) than required to take a decision within a particular context. Their request is based on their knowledge on available information (3) and on their understanding of the decision-domain (2). A part of the available and relevant information is not even requested (4). In case the available information (3) is not directly associated to the particular decision problem, it can be considered as pure data. Consequently, many entrepreneurial decisions are based on a fraction of the required information (5), and on irrelevant data (6). It is obvious that the functioning Management Information Logistics process is a prerequisite of decision support.

\section{THE DECISION DOMAIN OF THE EXTENDED ENTERPRISE}

With the Extended Enterprise concept aiming at an integration of customers, suppliers and final production via technological opportunities like the internet and the intranet, the issues of executive information, decision support and information management, i.e. the management information logistics process, do become even more crucial.

The reason being that complexity of the decision-domain is increasing with the number of parameters and their interdependencies to take into account. This is particularly valid for organisations with manufacturing operations. Figure 2 illustrates one possible view on the decision domain of the extended enterprise.

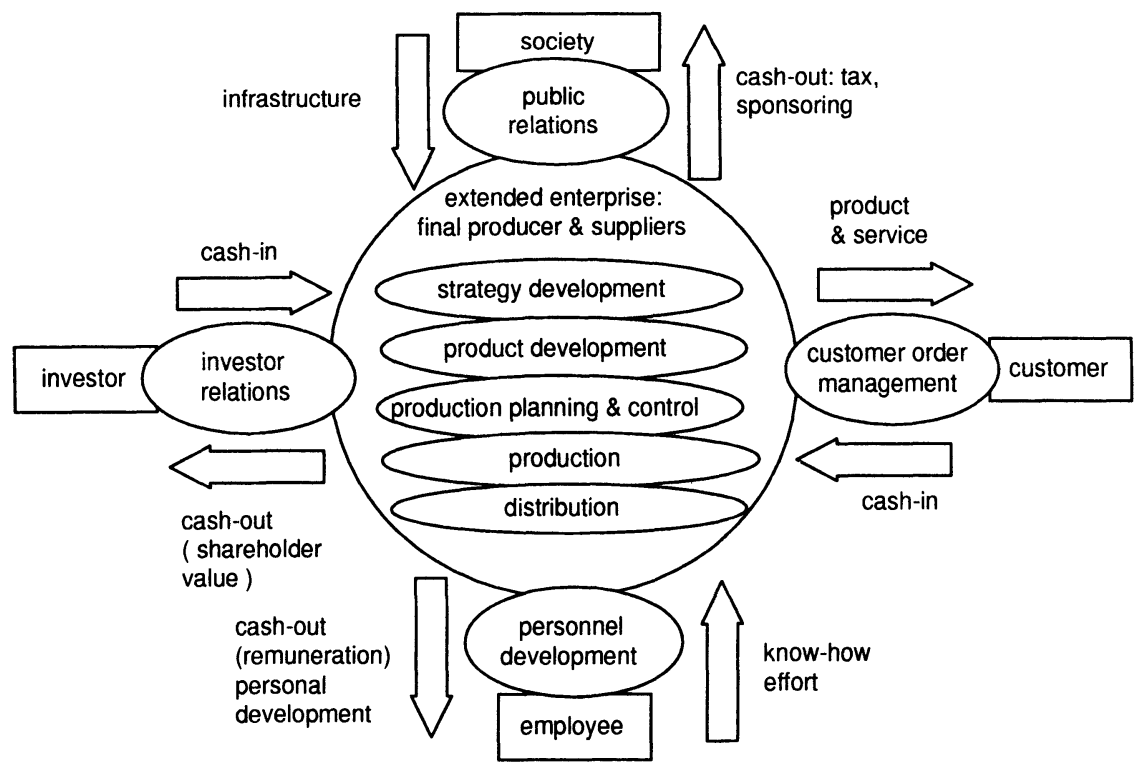

Figure 2 Stakeholders and core processes of the extended enterprise 
The extended enterprise consists of the operational processes strategy development, product development, production planning and control, production and distribution ${ }^{\prime}$. These processes link final producers and suppliers. Customers, investors, employees and society are stakeholders (Gomez 1993). The stakeholders interact with the extended enterprise via the processes:

- investor relations, which is the process to raise cash to fund new business opportunities by providing exceptional shareholder value which is equal to the discounted free cash-flow. This financial parameter describes the cumulated amount of money which a business will return to its investors until it has reached the end of its life-cycle.

- customer order management, which is the process to generate cash-flow by providing products and services to the customer,

- personnel development, which is the process to source know-how and effort by providing remuneration and personal development opportunities,

- public relations, which is the process to ensure appropriate infrastructure in terms of transport facilities, legal security, education and other by tax-payment and the generation of a positive image by sponsoring-activities.

Most companies realised that new organisational structures are required to manage the increasing complexity of the value chain (Mertins 1997). The answer to this challenge have been a considerable amount of organisational and control concepts.

\section{ORGANISATIONAL CONCEPTS AND CONTROL ASPECTS}

Some examples for organisational concepts with a considerable influence on management and company structure are:

- the Value Chain approach (Porter 1985)

- the Business Process concept (Hammer 1990),

- the japanese Bionic Manufacturing-approach

- the Modular Company (Wildemann 1992)

- Agile Manufacturing (Kidd 1994)

- the Fractal Company (Warnecke 1993),

- the Virtual Organisation approach.

All these concepts aim at an increase of effectiveness and efficiency. The most relevant paradigms which have been introduced with these concepts are:

\footnotetext{
'There is no unanimously agreed definition of a process framework in the literature so far. This is certainly a field for further research.

${ }^{2}$ Competitors are not mapped at this level. They can be seen as an issue at the strategy development level.
} 
- the decentralisation principle aiming to reduce non-value adding administration through delegation of responsibility to the process owners and to increase effectiveness through complexity-reduction,

- the core competencies principle aiming to establish a competitive advantage through focus on the improvement of those processes where the organisation can add the highest value to the product it is selling to the customer,

- the process orientation principle aiming to establish a holistic systems thinking through output and customer focus, and

- the pull-control principle aiming to produce only what is directly required by the internal or external customer in the next step of the value chain leading to minimised stock levels.

Decision problems are usually not very well structured and therefore a wide range of methods and tools to support decision-making and thus to support organisational control have been developed. Their goal is to reduce complexity and as a consequence to reveal the structure of a decision problem. The process of complexity-reduction with a decision-support methodology or tool can be seen as a modeling process. The underlying aim is to prevent the process owner from cognitive stress and to enable him to judge the decision-situation adequately.

Some of the most relevant planning approaches and concepts are:

- strategic planning methods like the scenario technique (Godet 1987), networkthinking (Probst 1991), portfolio techniques (Gomez 1993)

- Methods and tools for goal setting (Qualit 1996). They focus on hierarchical goal trees

- Operations research methods which are deterministic mathematical models of reality (Wild 1991)

- Multi-agent-approaches which are based on the blackboard architecture known from knowledge-based systems (Wild 1991)

- Production planning and control concepts (Mertins 1996)

- the MRPI and II approaches which are typical push-concepts

- the kanban-principle which is a typical pull-concept

- special approaches like Wiendahls charge oriented production control which is based on the funnel-principle (Wiehdahl 1992, 1995).

Some characteristic representatives of performance measurement systems are (Staudt 1984):

- the Du-Pont system of financial control which is a pure calculation scheme

- the Pyramid Structure of Ratios

- the Managerial control Concept

- the Ratios au Tableau de Bord

- the GS-System which is a modular system

- the ZVEI-system is a mixed modular and calculation scheme 
Besides these systems there are numerous more or less exhaustive performance measure-lists, which cover either functional areas like logistics, or are focusing on financial parameters (Kralicek 1995, Tschandl 1994).

A shortcoming of these approaches is the missing link between financial and operations view.

Two well-known representatives of performance measurement-frameworks are:

- the Balanced Scorecard

- the EFQM-model

Both do not suggest any particular performance measures, but rather provide guidelines for the development of a performance measurement system.

The control system and its effectiveness and efficiency remains a key aspect of any organisation. This is becoming particularly obvious with the implementation of the decentralisation-principle mentioned above.

The basic idea with this approach is, that partly autonomous units can be more easily controlled than large complex units due to reduced complexity. However, this is only true at the unit-level. The key problem is to assure that decisions at the partly autonomous units are in line with the objectives at corporate level. An appropriate Management Information Logistics process needs to be implemented to support decision-making and cooperation at all levels of the organisation.

\section{MANAGEMENT INFORMATION LOGISTICS REQUIREMENTS}

A key element of the control system of the extended enterprise is the Management Information Logistics process. The objective of this process is to provide process owners with decision-relevant infomation. The goal-system and the performnace measurement system associated to it form the logical basis for the Management Information Logistics process. The structure of both is largely determined by the relative importance of the building blocks within the decision domain of the extended enterprise. This relative importance is subject to change over time.

Currently the key performance indicator of many companies quoted at stockexchange is shareholder-value. Their goal system is focusing on an optimisation of the investor-relations process. In the future other indicators might be developed and other building blocks might be considered more important or regain importance. Therefore, a core requirement for the management information logistics process is adaptability. This adaptability cannot be realised with the existing concepts. They are mostly hierarchically structured and relatively inflexible.

This perception has been confirmed through a range of projects conducted at IPK in the last years. With the approach and the results of a particular benchmarking project the essentials will be demonstrated. 


\section{BENCHMARKING AS A METHOD TO INITIATE MANAGE MENT INFORMATION LOGISTICS ENGINEERING}

\subsection{Benchmarking-basics}

A management concept which has gained widespread attention at a large number of companies is Benchmarking (Mertins 1995). Rather than a simple comparison of performance measures the method aims to:

- take into account non-financial measures and qualitative data,

- integrate branch-independent sources,

- explain differences rather than to purely document them,

- focus on those criteria which are most relevant to the customer,

- team-up line-managers and specialists with the core project-team,

- consequently look for implementation,

- implement a continuous process.

It is obvious that Benchmarking is not only looking for quick-wins. In essence it is aiming at a cultural change towards the learning organisation. Within the cycle of enterprise development, Benchmarking does in particular support the goal planning and strategy development phase.

\subsection{A benchmarking project: approach and results}

Competitors aiming to enter a highly profitable market with $30 \%$ reduced production cost was the reason for three established international companies of the construction supply industry to set-up a Benchmarking project for four business units manufacturing a core product range.

The modelling of the processes throughout the value chain with the method Integrated Enterprise Modelling (Spur 1996) was the first step in the approach to generate transparency. On a top level the core processes were mapped. In this project the team agreed to select acquisition, sales forecasting, customer order management, production planning \& control, production, supply and distribution as core processes. This top-level was detailed with up to 3 levels

On the basis of these process-maps performance measures were developed. In addition performance measures concerning the market structure and the margindistribution over the value chain were defined as benchmarks. Figure 3 illustrates the approach schematically. 


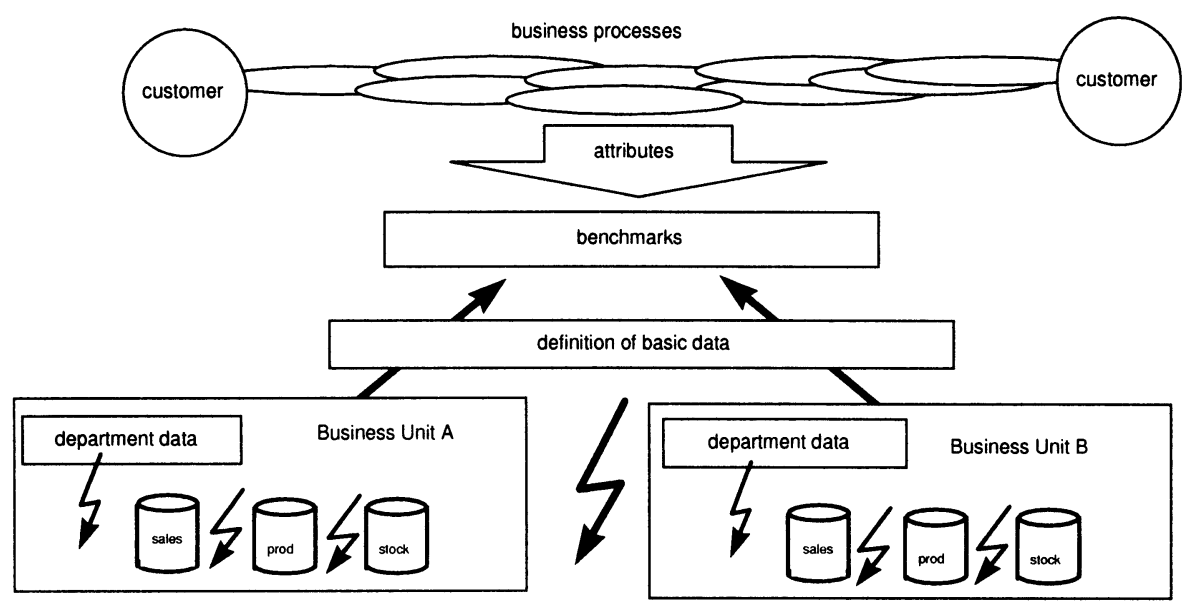

Figure 3 Schematic approach of process benchmarking

The exact definition of the performance measures and the basic data was a prerequisite to obtain comparable data from the four business units. The reason are the inconsistencies of the data-structure between and within the business units.

An example is the situation with the depreciation of production equipment which was completely incomparably handled for the business units according to their national depreciation policy.

Approximately 200 performance measures per business unit were defined. An aggregation of the detailed performance measures to the level of cost and profit performance measures with the process-categories, administration, acquisition, production planning and control, production with the sub-categories raw-material, maintenance, salary, machine-cost, packing, internal transport was developed. On the profit-side the distribution of margins over the value chain was compared for selected products.

On the basis of a scenario anticipating that each business unit could realise a costreduction per category to the level achieved by the most cost-effective business-unit in this benchmark-study, each business unit could achieve a cost-reduction of 40$45 \%$ of its total cost. For the margin-side a potential of up to $75 \%$ was identified.

Four realisation-projects have been initiated. The non-financial benchmarks are most important in this context. They are required to check the possibilities for a realisation of the identified potentials. An example is the cost-performance in acquisition which does not allow to judge the quality of this process if other benchmarks like market-penetration and market-potential are not taken into account.

This benchmark-project has clearly demonstrated the benefit of an analysis of the complete value-chain in comparison to a limited view on the production area, which was the first intention of the customer. The overall cost-reduction potential 
easily doubled the one identified in production. In addition, the margin-potential, which is twice the cost reduction potential in manufacturing, could be realised through better channel management and management of the product-range.

\subsection{Consequences}

The data-collection-phase with plausibility and consistency-checks did take approximately 5 months after the process models and the benchmark and basic-data definition were completed. During this phase the basic data has been exchanged completely or partly several times for each business unit. This time-consumption. again confirmed that the management information logistics process of most companies does not meet the requirements today.

Successful Benchmarking requires fast, and decision-relevant information. An evolutionary development of the Management Information Logistics process is characteristic for most companies. The initiation of Benchmarking projects can initiate a systematic engineering of the Management Information Logistics process.

\section{A MANAGEMENT INFORMATION LOGISTICS CONCEPT FOR THE EXTENDED ENTERPRISE}

With state-of-the-art technology it is possible to implement an integrated Executive Information System to supply departments, process-owners and top-management with decision-relevant and consistent information. Some technology-driven keywords in this context are data-warehousing and online-analytical-processing (OLAP) (Inmon 1993). The data-warehouse can contain quantitative data as performance and forecast-data as well as qualitative data as text, pictures and graphics. Both provide decision-relevant knowledge through the analysis tools which act as filters, figure 4 .

The terms Executive Information Systems and Management Information Systems both suggest a technology-centred view on the process of decision-relevant information-supply. Therefore, we suggest the term Management Information Logistics to describe the process of supply of relevant goal-oriented information and knowledge to process owners at all levels of the organisation. 


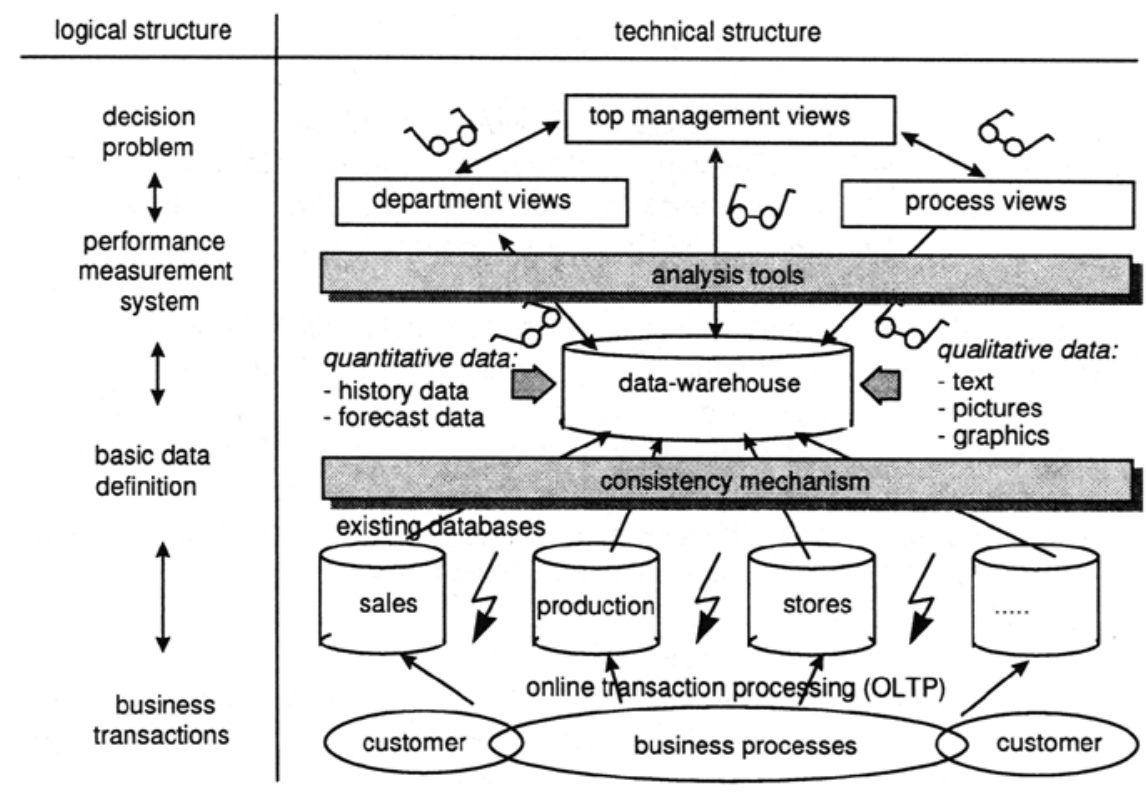

Figure 4 Logical and technical structure of the management information logistics process

Rather than technical issues and implementation tools, the challenge is to establish the logical structure of the Management Information Logistics process. Currently, there is no method providing appropriate support to generate the logical structure of a configurable control system which is the constituent part of the analysis tool. The same applies to the consistency mechanism which does contain the basic data definition.

The Management Information Logistics process is based on a network structure rather than on a hierarchical and inflexible structure known from traditional performance measurement systems.

The constituent components of this network oriented process control concept are

- a process network,

- an attribute network which is directly associated to the process network,

- a control parameter network where the control parameters are linked among each other and to the processes via the basic data elements (BD). The control parameters shall reflect the process-attributes,

- a goal network where the goals are linked among each other via the control parameters. 


\section{RESEARCH DIRECTIONS}

The frameworks for the development of a control system are situated on a rather high level. Hierarchical and logically structured performance measurement system are rather inflexible (Halloway 1995). A potentially successful approach to develop a method and a tool to support Management Information Logistics engineering can be outlined with the following steps:

1. review of the existing performance measurement and control concepts

2. development of a configurable business process model including a reference model for the information logistics process.

3. development of an adaptable control parameter framework on the basis of existing performance measurement frameworks from projects.

4. implementation of this structure in a configuration tool for process control parameters. This tool should include a possibility to link operational and financial parameters.

5. establishment of a link to a goal system editor

6. integration of tools for goal-planning, performance measurement and processmapping. The functional specification of such a tool should include views, what-if-scenarios, how-to achieve-scenarios and interval-reasoning.

Figure 5 summarises state of the art and potential research directions.

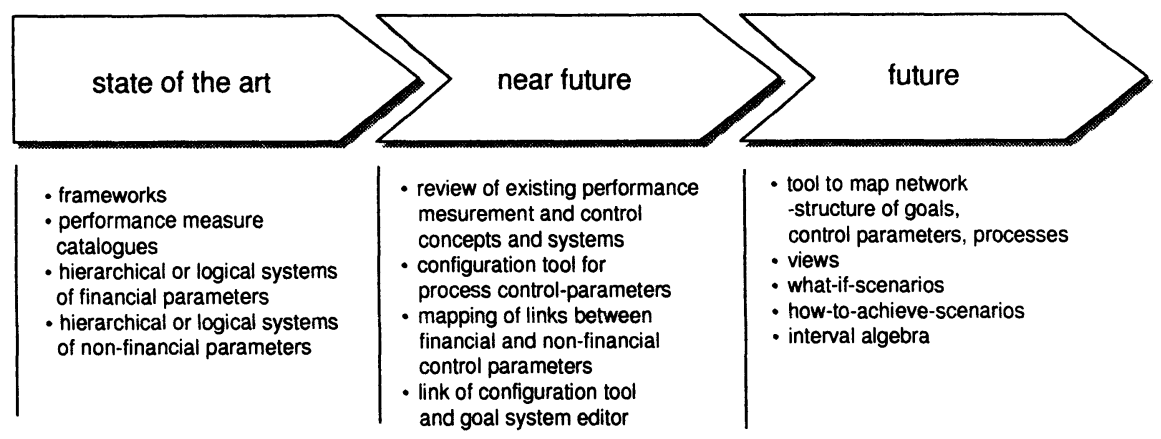

Figure 5 The next steps towards a process oriented control system

\section{REFERENCES}

Adam D., Planung und Entscheidung, Wiesbaden 1996, Gabler Godet , M., Scenarios and strategic management, 1987 London, Butterworth Gomez, P., Wertmanagement, 1993 Düsseldorf, Econ 
Halloway J. et al (eds.), Performance measurement and evaluation, 1995 London, Sage

Hichert R., Moritz M. (Hrsg.), Management-Informationssysteme, Berlin Heidelberg New York 1992, Springer

Inmon W.H. Building the Data Warehouse, New York 1993, John Wiley\&Sons

Groll K.-H. Erfolgssicherung durch Kennzahlensysteme, Freiburg, Haufe 1991

Kidd, P.T., Agile Manufacturing: Forging new frontiers, 1994 London, AddisonWesley

Kralicek P., Kennzahlen für Geschäftsführer, Wien 1995, Ueberreuter

Krcmar H., Annäherung an Informationsmanagement - Managementdisziplin und/oder Technologiedisziplin in Managementforschung 1 (1991), eds Staehle W.H. Sydow J., de Gruyter Berlin New York, p 163-203

Mascell B.H., Performance Measurement for World-Class Manufacturing, 1991 Portland, Productivity Press

Mertins, K., Albrecht, R., et al, Test and evaluation of factory control concepts by integrated simulation, 1996 29th International Symposium on Automotive Technology (ISATA) pp 221-227

Mertins, K., Heisig, P., Krause, O., Integrating business-process re-engineering with human resource development for continuous improvement, 1997 Internationa Journal of Technology Management Vol. 14 No 1 pp 39-49

Mertins, K., Siebert, G.E., Kempf, S. (eds.), Benchmarking: Praxis in Deutschen Unternehmen, 1995 Heidelberg, Springer

Probst G., Gomez P. (Hrsg.), Vernetztes Denken, 1991 Wiesbaden, Gabler

Porter M.E., Competitive Advantage, New York 1985, The Free Press

Schott G., Kennnzahlen - Instrument der Unternehmensführung, 1991 Wiesbaden Forkel

Spur, G., Mertins, K., Jochem, R., Integrated Enterprise Modelling. eds. Warnecke, H.J., DIN Deutsches Institut für Normung, 1996 Berlin, Beuth

Staudt E. et al, Kennzahlen und Kennzahlensysteme, Beflin 1985 Erich Schmidt Verlag

Tschandl G., Betriebsanalysen, Wien 1994, Ueberreuter

Verband deutscher Maschinen- und Anlagenbauer, (Hrsg.), Kennzahlenkompaß, Franfurt am Main 1993, Maschinenbauverlag

Warnecke H.J., The Fractal Company: A Revolution in Corporate Culture 1993 Berlin, Springer

Wiendahl H.-P., Anwendung der belastungsorientierte Fertigungssteuerung, München Wien 1992, Hanser

Wiendahl H.-P. et al, Engpassorientierte Logistikanalyse auf der Basis von

Betriebskennlinien, , io Management Zeitschrift 64 (1995) Nr 5 p27ff

Wild, R., Production and Operations Management, 1991 London, Cassell

Wildemann, H., Die Modulare Fabrik, 1994 München, TCW 


\section{BIOGRAPHY}

Dr.-Ing. Kai Mertins, born in 1947, studied Control Theory in Hamburg and Economy together with Production Technology at the Technical University of Berlin. In 1978, he became member of the scientific staff of the University Institute for Machine Tool and Manufacturing Technology (IWF), Berlin. Since 1983 he had been head of the department "Production Control and Manufacturing Systems" at the Fraunhofer-Institute for Production Systems and Design Technology IPK (President: Prof. Dr. h.c. mult. Dr.-Ing. G. Spur), Berlin, where he is Director of the Division Systems Planning since 1988.

Dipl.-Ing. M.Sc. Oliver Krause, born in 1965, studied Mechanical Engineering with majors in Production Management and Design Technology both with a focus on computer science aspects. Besides his diploma in Mechanical Engineering from Stuttgart University and Ecole Centrale Paris, he holds an M.Sc. in Advanced Manufacturing Systems from Brunel University London. Before joining IPK's Division Systems Planning, he worked on project assignments in London and Paris. He has been project manager for national and international projects. His research interest is focusing on management information logistics, decision support, performance indicators and information management. 